\title{
AVALIAÇÃO DO POTENCIAL ANTI-TIROSINASE E CITOTÓXICO DE EXTRATOS DE PIMENTA PSEUDOCARYOPHYLLUS (GOMES) LANDRUM
}

\author{
Rayane O. Mota ${ }^{1}$, Paulo R.H. Moreno ${ }^{2}$, Cynthia Murakami ${ }^{3}$, Maria C.M. Young ${ }^{3}$, Paola C. Branco ${ }^{4}$, Letícia V. \\ Costa-Lotufo ${ }^{4}$, Fabiana L. Silva ${ }^{1,2 *}$ \\ 1 - Faculdade de Farmácia, Universidade Paulista (UNIP), Santana de Parnaíba, SP \\ 2 -Instituto de Química, Universidade de São Paulo (USP), São Paulo, SP \\ 3 -Instituto de Botânica do Estado de São Paulo (IBt), São Paulo, SP \\ 4 -Instituto de Ciências Biomédicas, Universidade de São Paulo (USP), São Paulo, SP \\ falimasilva@hotmail.com
}

\begin{abstract}
Resumo: Substâncias fenólicas têm se mostrado como alternativas para o tratamento de transtornos não-malignos de hiperpigmentação. Pimenta pseudocaryophyllus é uma espécie nativa da Mata Atlântica que contém diversos compostos fenólicos e é reportada como ativa na redução de estresse oxidativo e inflamação induzida por radiação UV-B. No presente estudo, extratos de P. pseudocaryophyllus foram preparados e avaliados para atividades in vitro. O percentual de atividade antioxidante (em $100 \mu \mathrm{g} / \mathrm{mL}: 81-96 \%$ ) e anti-tirosinase (em $5 \mathrm{mg} / \mathrm{mL}: 41-60 \%$ ) foi próximo para todos os extratos, já a atividade citotóxica mais proeminente foi observada para o extrato clorofórmio (em $50 \mu \mathrm{g} / \mathrm{mL}$ : $94 \%$ ). Através da análise por CG-EM pode-se identificar eugenol, metileugenol e chavibetol como componentes majoritários deste extrato. Para avaliar a atividade desses compostos sobre a enzima tirosinase foi utilizado modelo in silico de docagem molecular com tirosinase de cogumelo. Eugenol mostrou a melhor classificação como inibidor e interações por ligação de hidrogênio e íon-dipolo, favoráveis à atividade inibitória.
\end{abstract}

Palavras-chave: Pimenta pseudocaryophyllus, CG-EM, citotoxicidade, inibição da tirosinase, docagem molecular.

\section{Evaluation of anti-tyrosinase and cytotoxic potential of Pimenta pseudocaryophyllus (Gomes) Landrum extracts}

\begin{abstract}
Phenolic compounds have been shown to be alternatives for the treatment of non-malignant hyperpigmentation disorders. Pimenta pseudocaryophyllus is a native species of the Atlantic Forest that contains several phenolic compounds and it is reported to be active in reducing oxidative stress and inflammation induced by UV-B radiation. Extracts from $P$. pseudocaryophyllus were prepared and evaluated for in vitro activities. The percentage of antioxidant activity (in 100 $\mu \mathrm{g} / \mathrm{mL}$ : $81-96 \%$ ) and tyrosinase inhibition (in $5 \mathrm{mg} / \mathrm{mL}: 41-60 \%$ ) was similar for all extracts, and the most potent cytotoxic activity was observed for the chloroform extract (in $50 \mu \mathrm{g} / \mathrm{mL}$ : $94 \%$ ). Through GC-MS analysis it is possible to identify eugenol and its derivatives methyl eugenol and chavibetol as major components. To evaluate the activity of these compounds on the tyrosinase enzyme, an in silico molecular docking model with mushroom tyrosinase was used. Eugenol showed the best classification as inhibitor and hydrogen bond and ion-dipole interactions, favorable to inhibitory activity.
\end{abstract}

Keywords: Pimenta pseudocaryophyllus, GC-MS, antioxidant activity, cytotoxicity, tyrosinase inhibition, molecular docking.

\section{Introdução}

Melanina é o pigmento responsável por proteger a pele de raios ultravioleta, formadores de espécies reativas de oxigênio (EROS), que podem causar câncer de pele. A sua superprodução resulta em hiperpigmentação, manchas ou melasma e o tratamento geralmente está associado ao uso de medicamentos ou cosméticos contendo agentes despigmentantes, que podem atuar por diferentes mecanismos de ação. A enzima tirosinase é uma metaloenzima que ocorre em vários organismos e participa de alguns estágios da melanogênese, por isso é um dos alvos mais investigados no bloqueio 
à biossíntese de melanina. Dentre os inibidores de tirosinase utilizados atualmente, um grande número é derivado de fontes naturais, como hidroquinona e ácido kójico, entretanto eles apresentam limitações com relação à alta toxicidade, baixa estabilidade e penetração reduzida na pele. Uma das alternativas a esses agentes são extratos vegetais contendo polifenóis, capazes de modular o metabolismo de pigmentação da pele. ${ }^{1}$ Pimenta pseudocaryophyllus (Gomes) Landrum (Myrtaceae) é a única espécie do gênero Pimenta Lindl. encontrada no Brasil. Ela é uma árvore de pequeno porte típica da Mata Atlântica. Apresenta três quimiotipos, determinados pelo predomínio de classe de metabólitos encontrados no óleo das folhas: citral (predomínio de monoterpenos), $(E)$-cariofileno (predomínio de sesquiterpenos) e (E)-metil isoeugenol (predomínio de fenilpropanoides). Extratos da folha de $P$. pseudocaryophyllus desses quimiotipos apresentaram atividades inibidora do estresse oxidativo e da inflamação induzida por radiação UV-B e antinociceptiva, mostrando substâncias fenólicas como principais constituintes. ${ }^{1}$ Considerando a riqueza da biodiversidade da Mata Atlântica associada à promoção de ações sustentáveis, esse estudo visa avaliar o potencial antioxidante, inibidor da tirosinase de cogumelo e a citotoxicidade de extratos de $P$. pseudocaryophyllus com o intuito de aplicação em formulações antipigmentantes que possam agregar valor para essa espécie nativa de importância para a região sudeste.

\section{Experimental}

\section{Preparo dos extratos orgânicos}

Cerca de $55 \mathrm{~g}$ de extrato hidroetanólico de folhas de Pimenta pseudocaryophyllus (coletada em: Vila Bonsucesso, Guarulhos - 2323'21'S 4625'31'W; identificada por: Profa. Dra. Sueli Nicolau, Instituto de Botânica do Estado de São Paulo; depositada em: Herbário IBt sob código OEA 604), obtido de maceração com etanol $96 \%$, foi submetido a partição sólido-líquido com os solventes clorofórmio, acetato de etila e metanol, em ordem crescente de polaridade. A partição foi realizada três vezes com $200 \mathrm{~mL}$ de cada solvente e sistema em agitação constante por $15 \mathrm{~min}$. Após filtração, cada extrato foi concentrado até a secura para obtenção do rendimento [extrato clorofórmio (E-1): 5,9\%; extrato acetato de etila (E-2) : 5,8\%; extrato metanol (E-3): 54.2\%].

\section{Triagem fitoquímica preliminar}

Triagem fitoquímica qualitativa de E-1, E-2 e E-3 foi realizada por CCD com reativos de visualização para terpenos [sistema de solvente (ss): hexano-acetato de etila, 97:3; revelador: anisaldeído sulfúrico], flavonoides (ss1: acetato de etila-metanol, 90:10; ss2: acetato de etila-ácido fórmico-ácido acético-água, 100:11:11:27; revelador: NP/PEG 1\%) e triterpenos e saponinas (ss: clorofórmio-ácido acético-metanol-água, 64:32:12:8; revelador: Liebermann-Burchard). ${ }^{2}$ Solução-padrão de cada extrato foi preparada na concentração de $20 \mathrm{mg} / \mathrm{mL}$ de metanol. Cinco microlitros de cada solução foram aplicados em cromatoplaca de sílica gel60 $\mathrm{F}_{254}$ e desenvolvida em solvente adequado.

\section{Cromatografia a gás acoplada a espectrômetro de massas (CG-EM)}

E-1 foi analisado por CG-EM utilizando equipamento e método previamente reportado por nosso grupo. ${ }^{3}$

\section{Ensaios biológicos in vitro}

As triagens antioxidante e citotóxica foram realizadas seguindo metodologias previamente publicadas por nosso grupo. ${ }^{3}$ Para a atividade antioxidante, a concentração final no poço avaliada para cada 
extrato foi de $100 \mu \mathrm{g} / \mathrm{mL}$; o controle positivo foi quercetina. A citotoxicidade frente a linhagem celular de melanoma (SK-MEL-147) foi analisada nas concentrações de 50 e $5 \mu \mathrm{g} / \mathrm{mL}$. O controle positivo foi doxorrubicina. A capacidade dos componentes dos extratos em inibir a ação da tirosinase foi determinada através de método em microplaca descrito por Macrini et al. ${ }^{4}$ As amostras foram dissolvidas em Tween $20^{\circledR} / \mathrm{DMSO}(2: 8)$ e em seguida diluídas em tampão PBS (50 mmol/L, pH 6,8) para obter as concentrações finais no poço de 5;2,5 e 1,25 mg/mL. Ácido kójico foi utilizado como controle positivo.

\section{Docagem molecular}

Para avaliar se eugenol e seus derivados podem se ligar diretamente no sítio ativo da tirosinase, simulação de docagem molecular foi realizada usando o programa GOLD 2020.3.0. ${ }^{5}$ A estrutura cristalográfica de raio-X de tropolona em complexo com tirosinase de Agaricus bisporus foi obtida do Protein Data Bank (PDB 2Y9X, resolução: 2,78 Å). ${ }^{5}$ Para validação do protocolo foi utilizado o método de redocagem do ligante cristalográfico no sítio ativo, considerando bem-sucedida a solução com desvio da raiz média quadrática (RMSD) menor que $2 \AA$ em relação à posse observada na estrutura inicial. O programa Avogadro foi usado para criar as estruturas 3D. As águas moleculares e o ligante co-cristalizado foram removidos e os hidrogênios foram adicionados. Os ligantes foram configurados no programa MarvinSketch, ${ }^{5}$ e as estruturas foram criadas em 3D e minimizadas usando Avogadro. ${ }^{5} \mathrm{O}$ protocolo utilizou receptor rígido-ligante flexível, sítio de ligação com $10 \AA$ de distância da tropolona, função ChemPLP com repontuação ASP e algoritmo genético muito flexível. As interações ligante-receptor foram visualizadas por Discovery Studio Visualizer. ${ }^{5}$ Os parâmetros para comparar a capacidade inibitória dos compostos avaliados foram maior pontuação o tipo de interações intermoleculares observadas.

\section{Resultados e Discussão}

O estudo fitoquímico dos extratos de $P$. pseudocaryophyllus revelou que E-1 é predominantemente constituído de terpenos. E-2 apresenta os três tipos de metabólitos investigados, enquanto E-3 tem flavonoides e triterpenos/saponinas como principais metabólitos (Tabela 1).

Tabela 1- Triagem fitoquímica de extratos de P.pseudocaryoplyllus.

\begin{tabular}{lccc}
\hline \multirow{2}{*}{$\begin{array}{c}\text { Classes de } \\
\text { metabólitos }\end{array}$} & \multicolumn{3}{c}{$\begin{array}{c}\text { Extratos de Pimenta pseudocaryophyllus } \\
\text { (folha) }\end{array}$} \\
\cline { 2 - 4 } & E-1 & E-2 & E-3 \\
\hline Terpenos & + & + & - \\
Flavonoides & - & + & + \\
Triterpenos/saponinas & - & + & + \\
\hline
\end{tabular}

E-1: extrato clorofórmio; E-2: extrato acetato de etila; E-3: extrato metanol; $(+)$ :

Presença; (-): Ausência de compostos dessa classe de metabólitos.

E-1 também foi analisado por CG-EM, revelando a presença de 21 compostos, principalmente fenilpropanoides, como eugenol (2,08\%), seus derivados chavibetol $(10,87 \%)$ e metil eugenol $(32,69 \%)$, além de elemicina (8,09\%) (Tabela 2). O composto majoritário foi metil eugenol e este já foi descrito como majoritário para o quimiotipo coletado em Paranapiacaba - SP. ${ }^{6}$

Os resultados de triagem da atividade antioxidante pelo método de DPPH mostraram que E-2 foi o mais ativo, seguido de E-3 e E-1 (Tabela 3). E-2 e E-3 contêm flavonoides, compostos conhecidos 
por essa atividade. Eugenol e metil eugenol, presentes em E-1, também são potentes antioxidantes. ${ }^{6}$ A capacidade de compostos fenólicos em proteger contra o estresse oxidativo está relacionada à possibilidade de doar elétrons ou hidrogênios para radicais livres, transformando-os em compostos estáveis, e deslocar o elétron desemparelhado dentro de sua estrutura aromática. ${ }^{6}$

Tabela 2- Constituintes caracterizados no extrato clorofórmio de P. pseudocariophyllus usando CG-EM.

\begin{tabular}{cccc}
\hline No. & $\begin{array}{c}\mathbf{t}_{\mathbf{R}} \\
(\mathbf{m i n})\end{array}$ & Composto & $\begin{array}{c}\text { Área do pico } \\
(\mathbf{\%})\end{array}$ \\
\hline 1 & 5,88 & eugenol & 2,08 \\
2 & 6,02 & chavibetol & 10,87 \\
3 & 6,25 & metil eugenol & 32,69 \\
4 & 7,03 & (E)-metil isoeugenol & 0,76 \\
5 & 7,43 & elemicina & 8,09 \\
6 & 8,21 & (Z)-asarone & 0,64 \\
7 & 8,29 & veratrato de etila & 1,19 \\
8 & 8,45 & $\beta$-eudesmol & 1,24 \\
9 & 9,66 & criptomeridiol & 1,11 \\
10 & 10,18 & palmitato de metila & 4,34 \\
11 & 10,45 & ácido palmítico & 4,30 \\
12 & 10,65 & palmitato de etila & 7,91 \\
13 & 11,29 & heptanoato de etila & 0,57 \\
14 & 11,42 & fitol & 2,18 \\
15 & 11,74 & linolato de etila & 1,16 \\
16 & 11,77 & oleato de etila & 1,94 \\
17 & 11,93 & estearato de etila & 0,79 \\
18 & 13,05 & oleamida & 2,07 \\
19 & 14,53 & behenoato de etila & 1,57 \\
20 & 16,85 & $\alpha$-tocospiro A & 3,48 \\
21 & 17,14 & $\alpha$-tocospiro B & 5,30 \\
\hline
\end{tabular}

$\mathrm{t}_{\mathrm{R}}$ : tempo de retenção.
Tabela 3 - Percentual de atividades antioxidante, antitirosinase e citotóxica para extratos de $P$. pseudocaryophyllus.

\begin{tabular}{|c|c|c|c|}
\hline \multirow{2}{*}{$\begin{array}{c}\text { Extratos } \\
\text { e } \\
\text { padrões }\end{array}$} & \multicolumn{3}{|c|}{$\begin{array}{l}\text { Atividade antioxidante } \\
(\%, \bar{X})\end{array}$} \\
\hline & \multicolumn{3}{|c|}{$100 \mu \mathrm{g} / \mathrm{mL}$} \\
\hline E-1 & \multicolumn{3}{|c|}{81,2} \\
\hline E-2 & \multicolumn{3}{|c|}{95,8} \\
\hline E-3 & \multicolumn{3}{|c|}{95,3} \\
\hline \multirow[t]{3}{*}{ Quercetina } & \multicolumn{3}{|c|}{$3,8^{*}$} \\
\hline & \multicolumn{3}{|c|}{$\begin{array}{c}\text { Atividade anti-tirosinase } \\
(\%, \bar{X})\end{array}$} \\
\hline & $1,2 \mathrm{mg} / \mathrm{mL}$ & $2,5 \mathrm{mg} / \mathrm{mL}$ & $5,0 \mathrm{mg} / \mathrm{mL}$ \\
\hline E-1 & 17,3 & 27,1 & 43,5 \\
\hline E-2 & 17,3 & 31,3 & 41,1 \\
\hline E-3 & 1,9 & 4,7 & 59,8 \\
\hline \multirow[t]{3}{*}{ Ácido kójic } & \multicolumn{3}{|c|}{$11,8^{*}$} \\
\hline & \multicolumn{3}{|c|}{$\begin{array}{r}\text { Atividade citotóxica } \\
\text { (SK-MEL-147) }(\%, \bar{X})\end{array}$} \\
\hline & $5 \mu \mathrm{g} / \mathrm{mL}$ & \multicolumn{2}{|c|}{$50 \mu \mathrm{g} / \mathrm{mL}$} \\
\hline E-1 & 34,8 & \multicolumn{2}{|c|}{94,2} \\
\hline E-2 & 12,4 & \multicolumn{2}{|l|}{51,7} \\
\hline E-3 & 6,4 & \multicolumn{2}{|l|}{24,0} \\
\hline Doxorrubi & $\operatorname{cin}{ }^{\mathrm{C}}$ & \multicolumn{2}{|l|}{$2,7 *$} \\
\hline
\end{tabular}

${ }^{\mathrm{A}}$ Controle positivo para atividade antioxidante; ${ }^{\mathrm{B}}$ Controle positivo para atividade anti-tirosinase; ${ }^{\mathrm{C}}$ Controle positivo para atividade citotóxica; SK-MEL 147: linhagem celular de melanona humano; E-1: extrato clorofórmio; E-2: extrato acetato de etila; E-3: extrato metanol; *Resultados de $\mathrm{IC}_{50}$, com valores em $\mu \mathrm{g} / \mathrm{mL}$.

Além disso, as substâncias fenólicas podem atuar na quelação de metais de transição. Como a tirosinase contém cobre, compostos que reduzam esse íon metálico podem ser considerados como inibidores da enzima. ${ }^{6}$ Os resultados obtidos apontam E-3 como o extrato mais ativo, na maior concentração testada $(5 \mathrm{mg} / \mathrm{mL})$, entretanto, nas concentrações de 2,5 e $1,25 \mathrm{mg} / \mathrm{mL}$, E-1 e E-2 mostraram atividades próximas e maiores que E-3 (Tabela 3). Dentre os compostos majoritários identificados em E-1, apenas eugenol foi estudado em modelo in vitro de inibição da tirosinase, apresentando $\mathrm{IC}_{50}$ de $8,2 \mu \mathrm{g} / \mathrm{mL} .^{6}$ Todavia, flavonoides, observados em E-2 e E-3, são conhecidos por essa atividade 
A inibição da tirosinase e a ação sobre o estresse oxidativo são vias de interesse no tratamento da hiperpigmentação, pela redução/bloqueio do escurecimento da pele, porém a pigmentação excessiva já existente também precisa ser reduzida. Para isso, compostos devem atuar na degradação dos melanócitos e queratinócitos hiperpigmentados, células produtoras e armazenadoras de melanina, respectivamente. ${ }^{1}$ Nesse estudo, células de melanoma foram utilizadas para avaliar a citotoxicidade dos extratos de $P$. pseudocaryophyllus e a possibilidade de degradação de melanócitos. Pelos resultados, E-1 mostrou a maior citotoxicidade nas duas concentrações avaliadas, seguida de E-2 (Tabela 3). Eugenol e metil eugenol são citotóxicos frente a linhagens de melanoma, ${ }^{6}$ sugerindo que esses compostos também atuem sobre a linhagem SK-MEL-147.

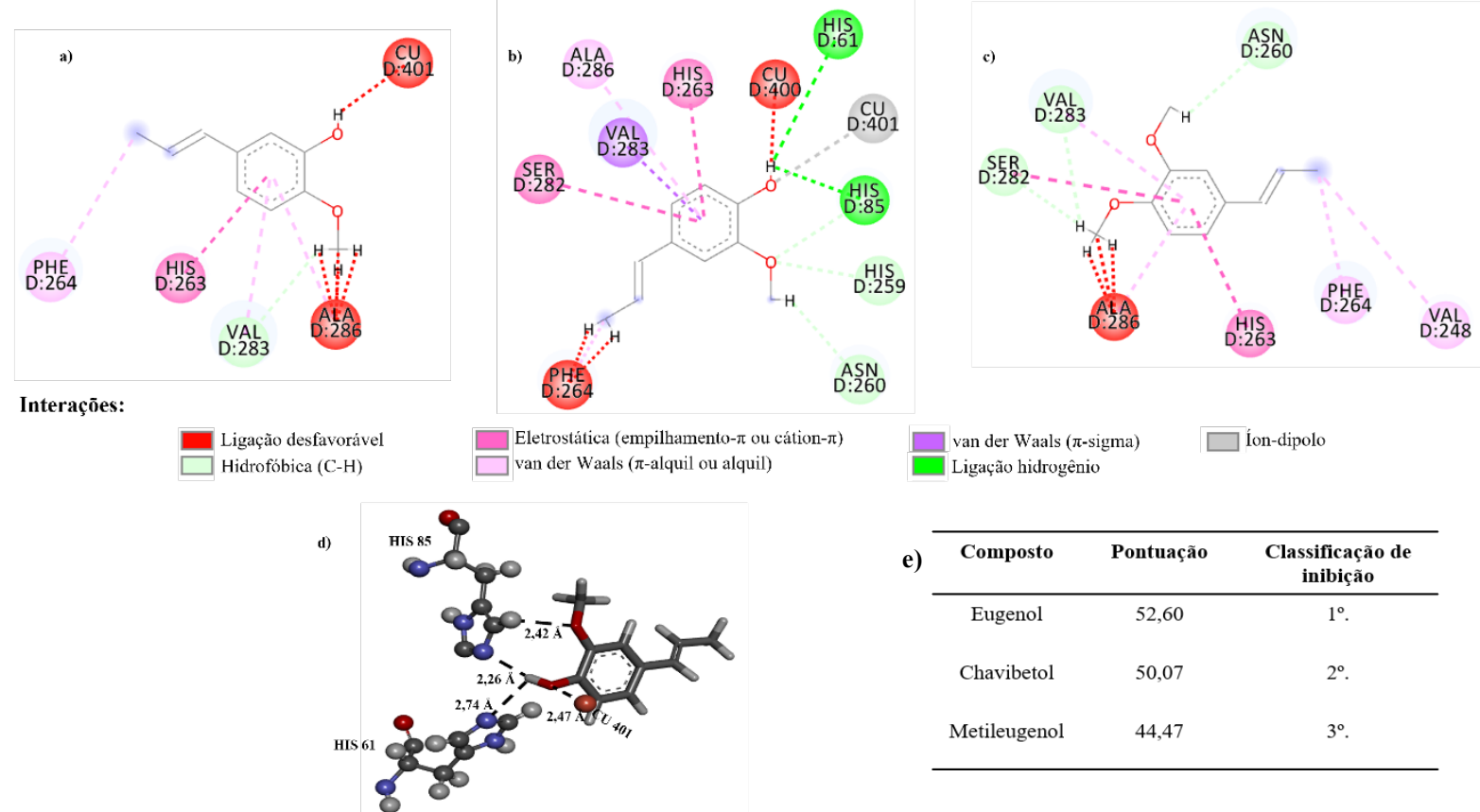

Figura 2 - Modo de ligação predito representado em estrutura 2D para a) Chavibetol, b) Eugenol e c) Metil eugenol no sítio ativo de tirosinase de Agaricus bisporus (PDB: 2Y9X); d) Representação em estrutura 3D das ligações hidrogênio e íon-dipolo com eugenol; e) Pontuação de docagem e classificação de inibição para os ligantes testados.

O extrato E-1 apresentou atividades antioxidante, anti-tirosinase e citotóxica. Como eugenol e metileugenol são conhecidos por diferentes atividades, eles e chavibetol (outro composto majoritário e derivado de eugenol) foram selecionados para análise de docagem molecular, para entender suas atividades sobre a enzima tirosinase. O protocolo utilizado foi validado por redocagem, apresentando RMSD de $0,71 \AA$ em relação à estrutura obtida por difração de raios X. O ligante de maior pontuação usando GOLD foi eugenol (Fig. 2e). Todos os ligantes testados apresentaram ligações desfavoráveis (Fig. 2a-c), o que pode afetar a estabilidade da atividade inibitória, já que esse tipo de ligação indica força de repulsão. ${ }^{7}$ Entretanto, para eugenol foram identificadas duas ligações hidrogênio envolvendo os $\mathrm{N}$ da cadeia lateral de His 61 e His 85 e a hidroxila fenólica do ligante, o que contribui para o aumento do grau de afinidade deste composto para o sítio de ligação (Fig. 2d). O posicionamento da hidroxila fenólica de eugenol na cavidade de ligação também foi responsável por outra interação importante, íon-dipolo com $\mathrm{Cu} 401$, o que pode potencializar a atividade inibitória (Fig. 2d). 


\section{Conclusões}

Os extratos de P. pseudocaryophyllus mostraram-se ativos nos testes antioxidante, anti-tirosinase e citotóxico in vitro. Baseando-se nos compostos caracterizados para o extrato clorofórmio, identificaram-se três compostos possivelmente ativos como inibidores da tirosinase. Os resultados das simulações de docagem identificaram eugenol como o mais promissor. Entretanto, trabalhos futuros devem ser desenvolvidos visando identificar e isolar outros compostos ativos desses extratos, aplicação em formulações antipigmentantes.

\section{Agradecimentos}

Os autores agradecem o apoio financeiro e institucional da Vice-Reitoria de Pós-Graduação e Pesquisa da Universidade Paulista (UNIP), Instituto de Química (USP), Instituto de Botânica do Estado de São Paulo (IBt) e Instituto de Ciências Biomédicas (USP).

\section{Referências}

1. Solano, F.; Briganti, S.; Picardo, M.; Ghanem, G.; Pigment Cell Research 2006, 19, 550; D’Angelis, A.S.R.; Negrelle, R.R.B.; Revista Brasileira de Plantas Medicinais 2014, 16.

2. Wagner, H.; Bladt, S.; Plant drug analysis: a thin layer chromatography atlas, $2^{\text {nd }}$ ed.; Springer: Berlin, 2009.

3. Silva, F.L.; Silva, J.L.V.; Silva, J.M.; Marcolin, L.S.A.; Nouailhetas, V.L.A.; Yoshida, M.; Vendramini, P.H.; Eberlin, M.N.; Barbosa-Filho, J.M.; Moreno, P.R.H.; Brazilian Journal of Pharmacognosy 2017, 27, 346; Silva, F.L.; Santo, A.E.; Branco, P.C.; Costa-Lotufo, L.V.; Young, C.M.Y.; Murakami, C.; Cordeiro, I.; Nicolau, S.A.; Ishibaru, L.M.; Moreno, P.R.H.; Global Journal of Medical Research: B 2019, 19.

4. Macrini, D.J.; Suffredini, I.B.; Varella, A.D.; Younes, R.N.; Ohana, M.T.; Brazilian Journal of Pharmaceutical Sciences 2009, 45, 715.

5. Jones, G.; Willett, P.; Glen, R.C.; Leach, A.R.; Taylor, R.; Journal of Molecular Biology 1997, 267, 727; Ismaya, W.T.; Rozeboom, H.J.; Weijn, A.; Mes, J.J.; Fusetti, F.; Wichers, H.J.; Dijkstra, B.W.; Biochemistry 2011, 50, 5477; https://www.chemaxon.com, accessed in August 2021; Hanwell, M.D.; Curtis, D.E.; Lonie, D.C.; Vandermeersch, T.; Zurek, E.; Hutchison, G.R.; Journal of Cheminformatics 2012, 4; Dassault Systemes BIOVIA; BIOVIA Discovery Studio Visualizer v16.1.0.15350; Dassault Systemes, San Diego, CA, USA, 2015.

6. Lima, M.E.L.; Cordeiro, I.; Young, M.C.M.; Sobral, M.E.G.; Moreno, P.R.H.; Pharmacologyonline 2006, 3, 589; Gogoi, R.; Loying, R.; Sarma, N.; Begum, T.; Pandey, S.K.; Lal, M.; Curr. Pharm. Biotechnol. 2020, 21, 927; Fernandez-Panchon, M.S.; Villano, D.; Troncoso, A.M.; Garcia-Parrilla, M.C.; Critical Reviews in Food Science and Nutrition 2008, 48, 649; Amin, E.; Saboury, A.A.; Mansuri-Torshizi, H.; Moosavi-Movahedi, A.A.; Journal of Enzyme Inhibition and Medicinal Chemistry 2010, 25, 272; Khunkitti, W.; Veerapan, P.; Hahnvajanawong, C.; International Journal of Pharmacy and Pharmaceutical Sciences 2012, 4, 556; Kim, D.; Park, J.; Kim, J.; Han, C.; Yoon, J.; Kim, N.; Seo, J.; Lee, C.; Journal of Agricultural and Food Chemistry 2006, 54, 935; Arung, E.T.; Matsubara, E.; Kusuma, I.W.; Sukaton, E.; Shimizu, K.; Kondo, R.; Fitoterapia 2011, 82, 198.

7. Dhorajiwala, T.M.; Halder, S.T.; Samant, L.; Journal of Applied Biotechnology Reports 2019, 6, 101. 